\title{
Defense Mechanism and Optimism in Korean College Students
}

\author{
Eun-Joo Hong1, Hyo-Eun Kim², Jin-Kyung Kim ${ }^{3}$ \\ ${ }^{1}$ Department of Early Childhood Education, Eulji University, Seongnam, South Korea \\ ${ }^{2}$ Child Development Support Center, Euliji University, Seongnam, South Korea \\ ${ }^{3}$ Department of Early Childhood Education, Korean National Open University, Seoul, South Korea \\ Email: khe4444@hanmail.net
}

Received September 2014

\begin{abstract}
The objective of this study was to illustrate the relationship between optimism and defense mechanism in Korean college students. 332 student participants from " $A$ " University in Korea completed questionnaires from the Ewah defense mechanism and optimism measurement tool. This study analyzed the culled data and revealed general patterns of optimism and defense mechanism, as well as patterns based on gender. In addition, the study analyzed differences in defense mechanism, dictated by one's optimism level. Frequency, percentage, mean, standard deviation, and t-test were analyzed using SPSS 21.0. The results demonstrated that the operating defense mechanism in Korean college students were different for males and females in the categories of show-off, passive aggressive, denial, and identification. However, the level of optimism was identical for both genders. Defensive mechanisms based on optimism levels also varied significantly in controlling, distortion, altruism, humor, sublimation, and rationalization categories.
\end{abstract}

\section{Keywords}

\section{Korean College Student, Optimism, Defense Mechanism}

\section{Introduction}

College years are typically considered as the period between post adolescence and early adulthood where independent search for ego-identity and development into a more mature ego take place. However, college students in Korea tend to depend on their parents much longer compared to their counterparts in Western societies. Consequently, although they have reached a certain age and physiological development, they lack independence and maturity in the areas of the social, psychological, and financial. In other words, college students in Korea are ill prepared to embrace this new environment in which they must suddenly make decisions on their own. The Korean education system, which overemphasizes the college entrance exam throughout the middle and high school years, is the primary cause for this social phenomenon. Korean students acquire an education solely based on standardized exams, developing a passive attitude for learning. Given this predicament, the researchers had to pay attention to the concept of optimism, a Positive Psychology personality trait which helps to foster healthy development and adaptation. Optimism is a positive anticipation about future events that act as an important 
factor to help reduce maladaptive problems such as distress and interpersonal issues. The previous studies have discovered that optimistic college students received more social support, and scored higher in life satisfaction and academic achievement, and experienced fewer psychological challenges, including stress, depression, and loneliness. In addition, there was a positive correlation between optimism and psychological well-being [1].

On the other hand, defense mechanism refers to thoughts, emotions, attitudes, and behaviors that one uses in order to resolve conflicts that work at both the preconscious and unconscious levels of the mind [2]. Defense mechanism is a critical factor in identifying neurosis [3]. Similar to a personality trait, defense mechanism appears as a fixation in adulthood [4]; therefore, it is considered an important concept in understanding human behavior [5]. If defense mechanism patterns can be evaluated objectively, they can manifest an individual's adaptation patterns and personality types [6] and in-group members' characteristics, behavioral patterns, and adaptation mechanisms [7] [8].

This study set out to investigate characteristics and behavioral patterns of Korean college students based on their defense mechanism, and to determine whether an important correlation between optimism and defense mechanism exists. The research pursued the following questions:

1. How do optimism and defense mechanism vary by gender?

2. What are the differences in defense mechanism based on optimism?

\section{Method}

\section{A. Participants}

As shown in Table 1, 332 students—52 male and 280 female—from "A" University in Korea were selected to participate in this research.

\section{B. Research Tool}

1. Optimism test

The researchers of this study used Carver and Bridges Life Orientation Test-Revised (1994), adapted by Shin (2005) [9] to measure optimism. A total of 10 questions, of which numbers 1, 4, and 10 inquired about general positive expectations, and numbers 3,7 , and 9 predicted pessimism, were asked. The remaining 4 questions were designed to distract the participants so that they could not figure out the purpose of the study. The 5-point Likert Scale was used, and the scores ranged from 6 to 30, the higher scores denoting higher levels of optimism. The original measuring tool [10] had a reliability of 0.78, and Shin Hyun-Suk's adapted version (2005) [9] indicated 0.65 in optimism questions, and 0.60 in pessimism questions. A current study by Lee (2010) [11] proved 0.80 reliability, while this study demonstrated 0.75 in Cronbach's $\alpha$.

2. EDMT: Ewah Defense Mechanism Test

This study used the Ewha Defense Mechanism Test [2] in order to measure defense mechanism. The process of scoring tests and analyzing results also followed EDMT guidelines. The reliability of this test has been proved to be $0.66 \sim 0.88$ in split-half method, the test-retest method after 2 weeks which showed 0.72 reliability. The test was designed to examine adaptation and defense mechanism in Korean-specific context. The test consisted of 20 defense mechanism measurements, and every scale included 10 questions, for a grand total of 200 questions. The 5-point Likert Scale was used to calculate the scores, and the aggregate from all 10 questions made up the raw score. The revised score was applied afterward.

3. Data Analysis

Frequency, percentage, mean, standard deviation, and t-test were determined using SPSS 21.0 for data analysis.

\section{Results}

1. General tendencies of optimism and defense mechanism in college students.

Table 1. General quality. N = 332 .

\begin{tabular}{cccc}
\hline & Variable & N & \\
\hline \multirow{3}{*}{ Gender } & Male & 52 & 15.7 \\
& Female & 280 & 84.3 \\
& Total & 332 & 100 \\
\hline
\end{tabular}


Table 2 demonstrates that optimism scored a bit higher than average $(\mathrm{M}=3.17, \mathrm{SD}=0.35)$.

Table 3 displays the defense mechanism and its subordinate categories. Regression, reaction formation traits, and identification were the top three, while the least used defense mechanism were distortion, denial, and acting-out. Overall, regression was the most distinctive element while distortion was barely present.

2. Differences in optimism by gender

As Table 4 shows, there was difference in optimism based on gender.

3. Gender differences in defense mechanism

Table 5 displays significant differences in defense mechanism between male and female students. Male students applied more passive aggressive, denial, and rationalization, while female students relied on more identification and regression.

4. Defense mechanism based on optimism

In order to determine the differences of defense mechanism based on the level of optimism, the researchers divided the data into 2 different groups. 30\% of the participants who scored the highest in defense mechanism were selected to be the first group, and lowest 30\% were placed in the second group. Table 6 illustrates the t-test results: Lower optimism group displayed controlling, distortion, humor, and rationalization. And higher optimism group displayed altruism and sublimation. However, there was no significant difference in ego negative pattern of defense mechanism in terms of optimism level.

Table 2. Optimism. $\mathrm{N}=332$.

\begin{tabular}{ccc}
\hline Variable & $\mathrm{M}$ & SD \\
\hline Optimism & 3.17 & 0.35 \\
\hline
\end{tabular}

Table 3. Defense mechanism. $\mathrm{N}=332$.

\begin{tabular}{|c|c|c|c|c|c|c|c|c|c|}
\hline & & $\mathrm{N}$ & $\mathrm{M}$ & SD & & & $\mathrm{N}$ & M & SD \\
\hline \multirow{7}{*}{$\begin{array}{l}\text { Unstable } \\
\text { Sensitivity } \\
\text { Patterns }\end{array}$} & Acting-out & 332 & 5.41 & 2.50 & \multirow{7}{*}{$\begin{array}{l}\text { Ego } \\
\text { Exploration } \\
\text { Patterns }\end{array}$} & Controlling & 332 & 6.19 & 1.90 \\
\hline & Displacement & 332 & 5.64 & 2.32 & & & & & \\
\hline & Somatization & 332 & 6.05 & 2.42 & & Distortion & 332 & 5.00 & 2.16 \\
\hline & & & & & & Altruism & 332 & 6.18 & 2.04 \\
\hline & Dissociation & 332 & 6.31 & 2.10 & & Humor & 331 & 6.17 & 2.14 \\
\hline & Projection & 332 & 5.56 & 2.28 & & & & & \\
\hline & Passive Aggressive & 332 & 5.72 & 2.19 & & Sublimation & 332 & 6.02 & 2.45 \\
\hline \multirow{5}{*}{$\begin{array}{c}\text { Ego } \\
\text { Negative } \\
\text { Patterns }\end{array}$} & Reaction Formation & 332 & 6.47 & 1.99 & \multirow{5}{*}{$\begin{array}{c}\text { Behavior } \\
\text { Inhibition } \\
\text { Patterns }\end{array}$} & Denial & 332 & 5.19 & 2.33 \\
\hline & & & & & & Rationalization & 332 & 5.98 & 1.94 \\
\hline & Identification & 332 & 5.93 & 2.19 & & Suppression & 332 & 6.42 & 1.93 \\
\hline & & & & & & Anticipation & 332 & 6.01 & 2.18 \\
\hline & Regression & 331 & 6.75 & 2.22 & & Evasion & 330 & 5.75 & 2.24 \\
\hline
\end{tabular}

Table 4. Optimism, t-test results based on gender. $\mathrm{N}=332$.

\begin{tabular}{cccccc}
\hline & Gender & $\mathrm{n}$ & $\mathrm{M}$ & $\mathrm{SD}$ & $\mathrm{t}$ \\
\hline \multirow{3}{*}{ Optimism } & Male & 52 & 3.27 & 0.40 & $2.28^{*}$ \\
& Female & 280 & 3.15 & 0.33 & \\
\hline
\end{tabular}

${ }^{*} p<0.05$. 
Table 5. Defense mechanism, one-way ANOVA results on gender differences. N = 332 .

\begin{tabular}{|c|c|c|c|c|c|c|}
\hline \multirow{2}{*}{\multicolumn{2}{|c|}{ Defense mechanism }} & \multicolumn{2}{|c|}{ Male $(\mathrm{n}=52)$} & \multicolumn{2}{|c|}{ Female $(\mathrm{n}=280)$} & \multirow{2}{*}{$\mathrm{t}$} \\
\hline & & M & SD & M & $\mathrm{SD}$ & \\
\hline \multirow{6}{*}{$\begin{array}{l}\text { Unstable } \\
\text { Sensitivity } \\
\text { Patterns }\end{array}$} & Acting-out & 5.57 & 1.23 & 5.38 & 1.23 & 1.02 \\
\hline & Displacement & 5.44 & 1.18 & 5.73 & 0.98 & -1.89 \\
\hline & Somatization & 5.85 & 1.31 & 6.10 & 1.28 & -1.24 \\
\hline & Dissociation & 6.43 & 1.15 & 6.38 & 1.14 & 0.25 \\
\hline & Projection & 5.95 & 1.05 & 5.74 & 1.01 & 1.37 \\
\hline & Passive aggressive & 6.08 & 1.29 & 5.70 & 1.05 & $2.34^{*}$ \\
\hline \multirow{5}{*}{$\begin{array}{c}\text { Ego } \\
\text { Exploration } \\
\text { Patterns }\end{array}$} & Controlling & 6.18 & 1.07 & 6.22 & 1.02 & -0.26 \\
\hline & Distortion & 6.20 & .97 & 6.01 & 1.04 & 1.25 \\
\hline & Altruism & 6.12 & .95 & 6.18 & 1.10 & -0.35 \\
\hline & Humor & 6.36 & 1.27 & 6.21 & 1.13 & 0.88 \\
\hline & Sublimation & 5.85 & 1.14 & 5.88 & 1.02 & -0.18 \\
\hline \multirow{4}{*}{$\begin{array}{c}\text { Ego } \\
\text { Negative } \\
\text { Patterns }\end{array}$} & Reaction Formation & 6.47 & 1.03 & 6.48 & 0.89 & -0.06 \\
\hline & Show-off & 6.14 & 0.97 & 5.98 & 1.10 & 0.95 \\
\hline & Identification & 6.32 & 1.00 & 6.64 & 0.97 & $-2.21^{*}$ \\
\hline & Regression & 6.42 & 0.95 & 6.86 & 0.96 & $-3.04^{* *}$ \\
\hline \multirow{5}{*}{$\begin{array}{c}\text { Behavior } \\
\text { Inhibition } \\
\text { Patterns }\end{array}$} & Denial & 5.75 & 0.93 & 5.21 & 0.92 & $3.83^{* * *}$ \\
\hline & Rationalization & 6.33 & 0.86 & 5.94 & 0.84 & $3.13^{* *}$ \\
\hline & Suppression & 6.60 & 1.01 & 6.34 & 1.04 & 1.70 \\
\hline & Anticipation & 6.02 & 0.83 & 6.07 & 0.96 & -0.30 \\
\hline & Evasion & 6.25 & 1.04 & 5.75 & 0.93 & $3.46^{* *}$ \\
\hline
\end{tabular}

${ }^{*} p<0.05 ; \stackrel{* *}{p} p 0.01 ;{ }^{* * *} p<0.001$.

Table 6. Defense mechanism, t-test results based on optimism High 30\%, Low 30\%. N = 332 .

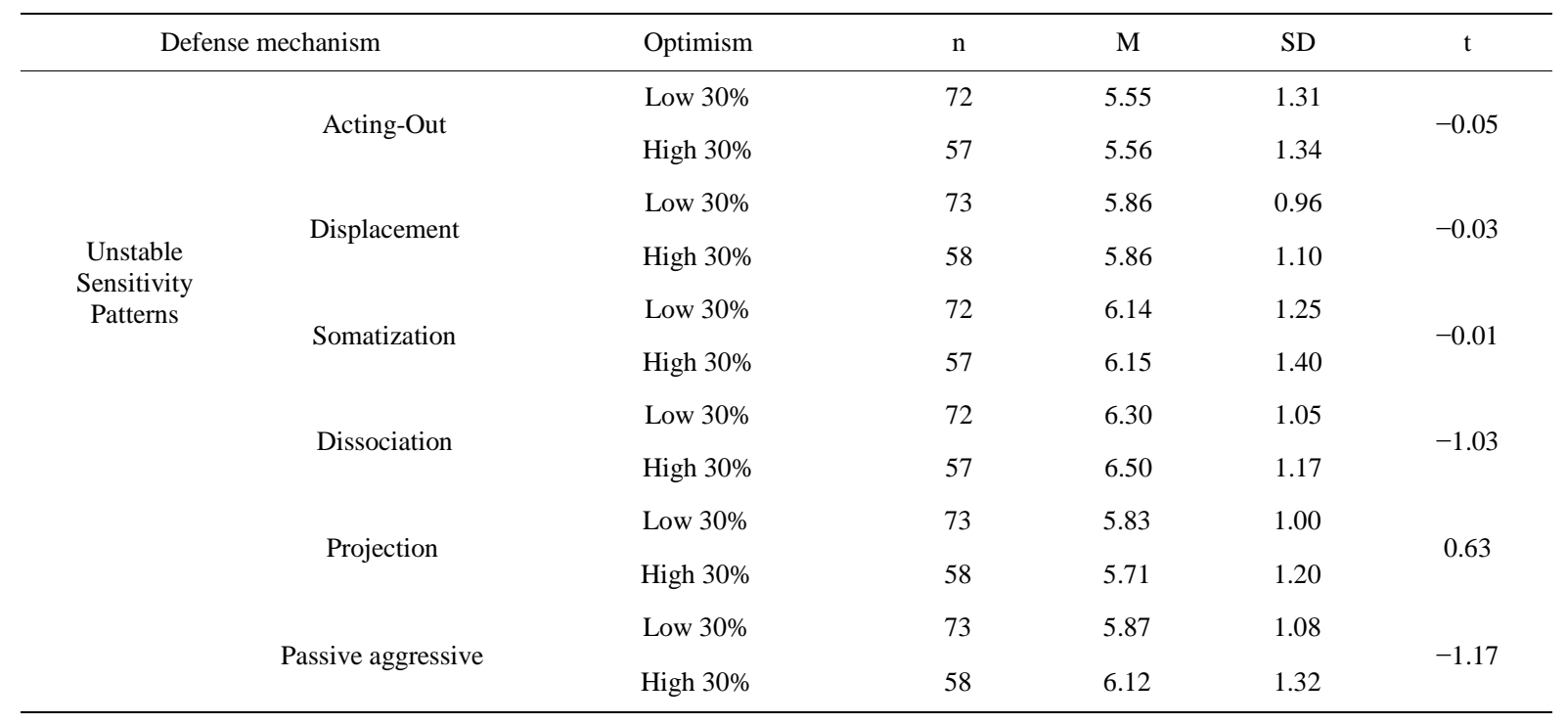




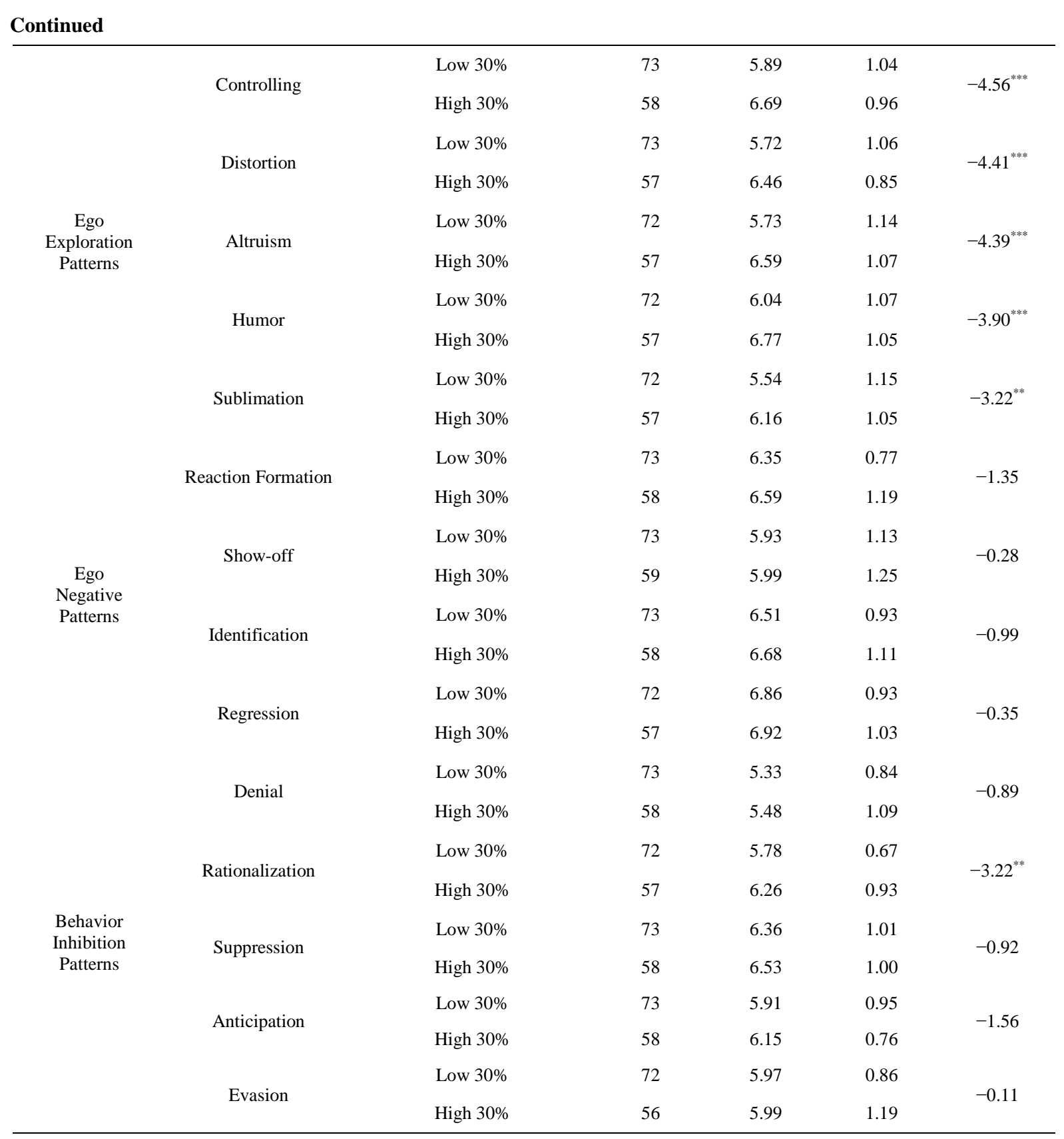

${ }^{*} p<0.05 ;{ }^{* *} p<0.01 ;{ }^{* * *} p<0.001$.

\section{Discussion}

The goal of this study was to demonstrate a relationship between optimism and defense mechanism in Korean college students, and the results revealed following.

First, Korean college students scored higher than average in optimism, and the women scored lower than men in optimism. Based on the Self-Control Behavior Model of Optimism, those with greater optimism exhibit superior skills in dealing with stressful situations, positive outlook, and possessing an optimistic view of reality. They are also confident in managing a variety of daily challenges effectively [15].

This study shows that Korean college students appear to be relatively positive. That female students scored lower in optimism is an indication that they lag behind their male counterparts in terms of coping skills, outlook, and perspective of reality. 
Defense mechanisms that Korean college students rely on most frequently are showing off, passive-aggressive, denial, and identification, in this order. This supports Kim Doo-Han's study (2004), which concluded that engineering students use denial within the Behavior Inhibition category and art students use showing off [2] [14].

Among the main categories of defense mechanism, the male students display unstable sensitivity, such as passive-aggressive and behavior inhibition, like denial or rationalization. The female students, on the other hand, rely on identification and regression. This shows that men depend more on the behavior inhibition mechanism, while female students opt for the passive defense mechanism. Hence the women are slightly less mature or independent [2] [12].

Second, the researchers divided the data into 2 groups based on average optimism — the top and bottom 30\% of participants—and analyzed the results.

The high group utilized all the ego exploration sub-categories: control, distortion, and humor. They also leaned on behavior inhibition, such as rationalization.

In addition, the top optimism group often used mature defense mechanisms, such as altruism and sublimation [13]. These results are in line with Kim Sang-In's study which determined that people with high optimism use mature defense mechanisms. Consequently, they are emotionally happier and psychologically healthier than those who rely on less mature defense mechanisms [16].

The limitation of this study: the researchers used collected data only from college students from "A" university in Korea. Therefore, applying these results to the general population might not be reliable.

\section{References}

[1] Kim, B.-H., Ann, Y.-J., Jung, M.-Y., Cha, J.-Y. and Choi, K.-W. (2004) A Study on the Relation between Level of Stress and Effects of Stress by University Students. Journal of Ewha Institute of Nursing, 38, 76-89.

[2] Kim, J.E., Lee, K.H., Kim, J.K. and Park, Y.S. (1991) Ewha Defense Mechanism Test. Hana-Euihak Press, Seoul.

[3] Freud, S. (1894) The Neuro-Psychosis of Defense. Ibid. 3.

[4] Kaplan, H.I. and Sadock, B.J. (1989) Comprehensive Textbook of Psychiatry IV. Williams \& Willkins, Baltimore.

[5] Brenner, C. (1976) Psychoanalytic Technique and Psychic Conflict. International University Press, New York.

[6] Maddi, S.R. (1980) Personality Theories. 4th Edition, The Dorsey Press, Illinois.

[7] Vaillant, G.E. (1981) The Natural History of Male Psychological Health. Arch Gen Psychiatry, 33, 433-440.

[8] Jung, H.Y., Hong, H.K., Kim, Y.R., Lee, S.Y., Jung, H.Y. and Han, S.H. (2002) A Study of Fellow and the Interns' Ego-Defense Mechanism: Comparing Physicians and Surgeons. Journal of the Korean Neuropsychiatric Association, 41, 298-308.

[9] Shin, H.S. (2005) Testing the Mediating Effect of Coping in the Relation of Optimism and Pessimism to Psychological Adjustment in Adolescents. Korean Journal of Youth Studies, 12, 165-192.

[10] Scheier, Carver and Bridges (1994).

[11] Lee, J.Y. (2010) The Relationship among Adult Attachment, Optimism and Social Anxiety of University Student. Master's Degree Thesis, Kyungsung University.

[12] Suh, K.H. and Oh, K.H. (2009) The Moderate Effect of Life Satisfaction Expectancy on Life Stress and Health among College Students. Journal of Korean Health Psychology, 14, 633-648.

[13] Kim, J.E., Lee, K.H., Kim, J.K. and Park, Y.S. (1991) A Study of Ewha Defense Mechanism Standardization Test. Journal of the Korean Neuropsychiatric Association, 30, 582-591.

[14] Kim, D.H. (2004) The Study on the Ego Defense Mechanism in Accordance with Factors Internal \& External of University Students. Master's Degree Thesis, Konkuk University.

[15] Scheier, M.F. and Carver, C.S. (1992) Effects of Optimism on Psychological and Physical Well-Being: Theoretical Overview and Empirical Update. Cognitive Theory and Research, 16, 201-228. http://dx.doi.org/10.1007/BF01173489

[16] Kim, S.I. (2009) Defense Mechanism \& Mental Health. Korea Whole-Person Educational Development Institute. 